\title{
"Everything": Towards an Ecology of Land Utilization
}

\author{
João Afonso Baptista
}

\begin{abstract}
In southeast Angola, there is a rural village known as Cusseque that, similar to many other societies, has developed a particular relationship with the surrounding landscape. In contrast to the prevailing literature on land practices, I attempt to demonstrate that the global circulating concept of "land use", which assumes the land is a field of human governance, is not appropriate for grasping this relationship. In Cusseque, I encountered a creative system of utilization based on residents' reliance on the virtues of the land's ability to self-govern. Therefore, I explore an alternative conceptual tool and demonstrate that, in addition to "land use" and other analytical constructs, we should view human ecology through the lens of land utilization. This perspective, I suggest, functions on the basis of relational complementarity among all the agents on the land as it realizes the living world as integrative.
\end{abstract}

Keywords: Africa; Angola; biological knowledge; ecological anthropology; honey; land valuation; non-human nature; relational materiality; values; wholeness.

“Tudo": Rumo a um Ecologia de Aproveitamento da Terra

Resumo: No Sudeste da Angola, há uma vila chamada Cusseque que, semelhante a muitas outras sociedades, desenvolveu uma relação especial com o meio envolvente. Em contraste com as práticas sobre a terra encontradas na literatura atual, tento aqui demonstrar que o conceito referente a "uso da terra" que circula mundialmente, e que define a terra como um domínio de governação humana, não é adequado para a compreensão desta relação. Em Cusseque, deparei-me com um sistema de aproveitamento criativo baseado na confiança que os moradores possuem em relação à capacidade e virtude da terra em autogovernar-se. Por isso, neste artigo elaboro uma ferramenta conceptual alternativa que tenta demonstrar que, além de "uso da terra" e outros conceitos analíticos, devemos considerar a ecologia humana sob o prisma do aproveitamento da terra. Tal perspectiva, sugiro, funciona com base na complementaridade relacional entre todos os agentes na terra uma vez que considera o mundo vivo como integrador..

Palavras-Chave: África; Angola; antropologia ecológica; conhecimento biológico; materialidade relacional; mel; natureza não humana; valores; valores da terra; totalidade.

Received: 06 August 2013 - Accepted: 22 November 2013

\section{Introduction}

"I hear voices in everything and dialogic relations among them."

(Bakhtin 1986: 169)

In this article, I describe some of the research I conducted in the village of Cusseque in southeast Angola. It summarizes the ethnographic work I developed for an interdisciplinary project, The Future Okavango (TFO). The content is primarily empirical, presented as a report, but which I believe is significant for those who work with or are interested in global environmental issues.

On the conceptual side, I wish to fill a disturbing gap in the literature related to rural "land use" which targets land exclusively as a means of human intervention, including the governance of humans' absence from the land for humanity's sake. According to this principle, even the value of "wildness" is driven by advanced regimes of environmental management. Perhaps more than in any other case, this is apparent in the production of natural conservation parks where long-term residents have to be resettled elsewhere by governments, global development institutions, or corporate-funded NGOs. Drawing on Pierre Lascoumes' work, Thomas Nail suggested this "eco-power" represents a second stage of biopolitics that extends the control of human society to all forms of life (2010: 179-180).

However, based on scientific accounts that highlight the dramatic deterioration of the "weather-world" (Ingold 2011[2000]), we have arrived at a stage that begs for the emergence of a new ecopolitics of emancipation. One question resides at the core of the contemporary environmental crisis: How can we better understand and enact our relationship to the land? Never the relationship between humans and non-human nature (the natural world that has not been shaped by humanity to achieve human-oriented ends [Hailwood 2012: 884]) required reconsideration as it does now.

I suggest we turn our attention to the role of the unruliness of the land as a means to provide livelihoods. I am not embarking on a criticism of "land use". Rather, my goal is to present a different way to look at the land by exploring its self-organizational attributes - attributes that would exist without human intervention.

The empirical accounts presented in this article were derived from direct research in Angola. Overall, it draws from data I "produced" as a participant observer during the following periods: between June and July 2011; during February, March, June, and July 2012; 
and in May 2013. More than relying on statistic indicators and other barometers provided through computer screens, the suggestions and reasoning I present here derive mainly from a proximal, direct, sensorial, and bodily form of thought. Along these lines, I refer to local natural resources in the language in which I learned about them (i.e. Utchokwe). In other cases, I note the use of different languages.

In this article, my intention is not to reinforce the extensive body of literature that, deliberately or inadvertently, naturalizes rural peoples in Africa as the exotic extension of nature. In general, this version of the continent and its peoples places African rural residents behind the always more progressive peoples in the Euro-North American context. It promotes dualism between "North" and "South" as well as between "human" and "natural" areas. In the next pages, I try to alienate from such a structural viewpoint, and I draw on ethnographic evidences from an Angolan village to provide arguments towards a broader model of social progress; more specifically, a model based on the blurring of boundaries between human and natural areas, and hypothetically more adjusted to the deteriorating conditions of the world at large.

The testimonies, materials, and experiences presented here demonstrate that the idea of defending, even partially, humans' provisions from nature to what nature can actually generate is not naïvely romantic but part of the conditions of possibility for social living. Indeed, a broader recommendation is implicit in the everydayness of Cusseque residents: In addition to managing the land admittedly, an inevitable requirement for human cohabitation - we should consider the potential inherent in liberating the land from humans' dominative impulses to organize. In other words, we should allow the land to regenerate itself through non-anthropogenic modes of reproduction that do not rely on subservience to humanity in a radical way (e.g. agriculture). This does not mean a separation between humans and (the rest of) nature, as if one was not associated with the other - "There is simply no way to disengage" (Jordan 2005: 198). Rather, I suggest the necessity of levelling sovereignties between humans and the land notwithstanding humans' dependency of it. Fundamentally, this approach provides a way to consider humans and all other organic life-forms from the dual perspectives heterogeneity and complementarity.

Before I proceed to the crux of the matter, allow me to introduce a semantic clarification. By utilization, I refer to the meaning of the Portuguese word aproveitamento, which, by itself, is already highly contextual. Basically, aproveitamento is an expression used to describe the holistic effect of utilization. It indicates the integration of a previously uninteresting given element into a resource. This definition surpasses connotations of "use" or "appropriation" and includes the notions of "relationship with" and "engagement in" the means aproveitados (utilized). More importantly, aproveitamento implies selfconscience during the act of utilizing or reutilizing something. It exceeds the passive action of just collecting. This is crucial to remember because the perspective of land utilization allows us to maintain a certain distance from the essentialist vision, similar to traditional archaeological and anthropological traditional thought, that recognizes only two ways of procuring livelihoods from the natural environment: collection or production (Ingold 2011[2000]: 77). To ensure clarity from the beginning, by land utilization, I mean more than collecting and producing but practices performed in virtue of a relational property that exists between humans and the non-human goods that are naturally, independently reproduced on the land. Therefore, implicit here is the advocacy of making a living in a world purposely not entirely of our making.

\section{Land Use versus Land Utilization}

The idea of "land use" is based on the belief in deliberate intervention "by people to produce, change or maintain a certain land" (FAO/UNEP, 1999: 7). It implies human planning, management, ranking, and a set of human rules that aim to achieve specific results. Land use relies on the social intentional will to master nature. As Van Diepen et al. described, it implicates "the allocation of land to various categories of use according to criteria formulated during the land evaluation process" (1991: 191). Hence, land use arises as a field which supports the production and establishment of means of commensurability that derive or ask for human controlling actions. Here, the land gains its value exclusively as a mouldable resource to be worked by men and women. It is a humanized and objectified entity of intervention that must be civilized.

In essence, within the domain of land use, earning a livelihood is inconceivable without reducing the land to the humanreigned world. This concept positions humanity on a pedestal that is deliberately higher than the natural world of the land. It might be hypothetically possible to justify this as the product of an ideology driven by humans' intimate fear of being left at the mercy of forces beyond their control (e.g. Bakhtin 2008). In particular, North Atlantic modernity involves humans' quest for predictability to annul the dangers of living in an unforeseen world; a process in which human beings attempt to rise above and control both their own nature and the nature around them. This crusade has been called progress and has been supported by the grand narrative that advocates for the human transcendence of nature.

Land utilization implies a different dialectic. It entails no premeditated human arrangements of the land for humans' sake. In this case, rather than serving as a reflection of human intentions, the land is valued in general as a resource by virtue of the way it rules itself. Moreover, in land utilization, the values of the land do not arise from its condition of being purposively left alone by humans, as described in environmental protection and conservation policies. Rather, land values arise from relational practices that develop between humans and non-human nature as long as the effects of these relationships occur in accordance with the land's selfreproductive capacity. Finally, land utilization is based on a broader interpretative assumption: more than downplaying the distinction between nature and "us", nature and culture, and nature and unnatural (cf. Harman 2005: 251) it operates from the perspective of relationality, which requires that humans live with the land in non-domineering ways. In line with Paul Rabinow's anthropology of contemporary, I raise the concept of land utilization "as a tool to advance inquiry rather than as ends in themselves" (2011: 122).

In Cusseque, the residents employ a peculiar pattern of adjectives and pronouns. Words such as "resisting", "all", "everywhere", and, particularly, "everything", were repeatedly used to describe everyday life. For example, in 
May 2013, after a ten-month absence from the village, I met a 52-year-old resident when I returned and simply asked him, "How are things with you and your family?" "'Éhh chára," he said, "You were gone for a long time. I continue resisting life here, as everything does." Indeed, "everything" (tudo, in the original Portuguese) was the most common pronoun used by the residents during conversations related to their families, themselves, and their values. It is as if it was by way of everything, of totality, of wholeness, rather than of fractions, sections, hierarchies, that the residents came to value subjects in everyday life. "Look, you have to understand that there are clevernesses [in the plural - espertezas, in the original] everywhere here", an elder told me after I asked him to identify the specific areas he valued most in the land. "Everything here is very important", he continued, "Everything is equally essential for us". In the following pages, I will attempt to make sense of this "everything" by employing the lens of land utilization. Hopefully, towards the end it will become clearer that and how the everything has its value because of everything around it. In land utilization, there is no dead background; "everything acts, everything takes part in the unified life of the whole" (Bakhtin 2008: 218).

\section{Historical Setting}

Angola gained independence on 11 November 1975, after enduring more than four centuries of unofficial and official occupation by the Portuguese. Independence was achieved after a decade of war that began with a popular uprising against forced labour in the province of Malange. Local workers began demanding better conditions and higher wages from the administrators of cotton plantations in which they worked. These requests soon escalated to the status of revolts and spread to other regions. Ultimately, a guerrilla war developed between the Portuguese Armed Forces and other dispersed armed groups. The conflict ended only after the Angolan factions, União Nacional para a Independência Total de Angola (UNITA), Movimento Popular de Libertação de Angola (MPLA), Frente Nacional de Libertação de Angola (FNLA), and the Portuguese government signed the Alvor Agreement on 15 January 1975. This accord granted Angola independence that would begin ten months after the date the agreement was signed.

However, in Angola, no rejoicing occurred. Even though independence was declared, a new civil war started. Beginning in November 1975, almost 27 years of intensive battles continued throughout the country, with the exception of some short peaceful intervals. These battles were power struggles fought primarily between MPLA and UNITA. The conflict created a structural division between urban and rural areas (Brinkman 2000:15). Although the forests were the privileged place of permanence for UNITA's military forces, the rural countryside became a field of human abandonment, left to itself.

These circumstances were especially obvious in the southeast region, in which the "rebels", as the UNITA's forces were known, became a prominent presence. Moreover, this region was unofficially institutionalized as "the lands at the end of the world" - a "zone of wildness". In his influential book firstly published in 1973, agronomist Castanheira Diniz stated that, since colonial times, the southeast had been placed in the public imagination as a terrain of "impressive vastness of horizons" which included "long distances and the difficulties in overcoming them; the immense spaces rarefied of human presence, the nativeness of the local populations and the almost total preservation of the natural environment" (2006[1973]: 455). Although local inhabitants became known for their "reduced subsistence agriculture, based on crops undemanding to land", during the colonial period, Diniz said, this region was characterized by the "notable [human] activity of utilization of nature's resources ... supplying them the necessities of proteins ... steeply during the year" (Ibid. 457). In other words, relationships of the resident population with the land extended beyond the common categories of farmers or hunters and gathers. These residents were recognized as not acting specifically on the land, but rather complementarily.

The village of Cusseque is located in southeast Angola. It originated out of this historical conjuncture, as well as from the period of public suffering that occurred during the post-colonial construction of the nation. Specifically, the civil war created the village as it is currently. On 20 July 1979, the political party MPLA placed a group of men who originated from the surrounding communes of Mumbué and Mutumbo on the banks of the river Cusseque. "Only animals and trees were here", a long-term resident stated. At that time, the majority of the population of southeast Angola had migrated to neighbouring countries or resettled in larger settlements in which they felt more protected from the civil war. The landscape of the countryside became the ultimate space for battle; a dangerous area that common citizens would avoid.

However, while most Angolan civilians were leaving their rural areas of origin, other Angolans were recolonizing these abandoned areas. These civilians had been constituted as military forces. It was precisely this context of warfare and the militarization of certain individuals that led to the emergence of Cusseque's society. These people who resettled the emptied rural area by the civil war were integrated into the MPLA party's army, the Forças Armadas Populares de Libertação de Angola (FAPLA), and assigned one task: to protect the existing colonial road-bridge that spanned the river Cusseque from the armed forces of the political party in opposition, the UNITA. Owing to their isolation from other populations, the land that surrounded them, which they were unable to cultivate or pasture cattle because of the war, soon became their biggest ally. These residents had to rely on the land's unmanageable capacity to make an everyday living.

In 1992, because of seasonal floods, individuals who resided in Cusseque decided to move to higher ground located roughly 650 meters north of the banks of the river. This migration reinforced the institutionalization of their presence beyond military purposes. Hence, Cusseque was popularly recognized as a village in its own right. "Slowly, after our ladies and relatives came to join us, the village of Cusseque became definitive and it is resisting until today", a resident said. The character of war, spatial isolation from other populations, and reliance on untamed land became central to the historical constitution of the Aldeia de Cusseque (Village of Cusseque).

In 2011, the local Secretary at that time (MPLA's representative in the village) stated that Cusseque had a population of 520 people distributed through 110 households. Most residents spoke Utchokwe, although some inhabitants also communicate in Ngangela, Umbundu, and Portuguese. Nearly all the residents were Tchokwe, also known as Quiocos or Badjok in the neighbouring 
Democratic Republic of the Congo. Generally, the Tchokwe were associated with the northeast Angola in the provinces Lunda Sul and Lunda Norte. However, because of pre-colonial migratory movements, some Tchokwe established residence in the southeast region, an area in which another ethnic group, the Ganguela, prevail. The Tchokwe have been known since colonial times for "their great capacity of adaptation to various contexts" (Diniz 2006[1973]: 375). Therefore, in public discourses, they are commonly associated with nomadism. This is particularly apparent in their relationships with the land. For example, when I approached the Director of the Department of Agriculture in the Municipality of Chitembo to discuss the cyclical rotation of the agricultural fields in Cusseque, he explained, "That's because they are nomads, so it's natural for them to circulate on the land".

It might be worth expanding on Cusseque's association with nomadism because it can provide more information related to the nature of local perceptions of the land. According to Julian Steward (1970: 119), the spirit of nomadic mobility suggests the absence of the will to build defensive infrastructures. It is the sedentary impulse that contributes to the development of a territorial attitude, primarily through the construction of defensive buildings, distinct architecture, or monuments to identity that symbolize cultural uniqueness. On the contrary, as I developed elsewhere in the context of Chinese entrepreneurs in Portugal (Baptista 2006: 136-137), less sedentary groups have a greater tendency towards marking the land based on its capacity to provide means for a living, or even feeling "at home" with the untamed, rather than demonstrating a tendency toward constructing (on) the land to produce provisions from it. Note that I am not arguing that contemporary Cusseque engages in land practices that are crucially distinct from routines in other surrounding villages where the Guanguelas, who are more frequently associated with sedentary habits, predominate. What I argue, however, is that there is a distinct significance attributed to the land by the inhabitants of Cusseque because of their nomadic background along with the articulations made between the constitutional factors central to the foundation of the village. Perhaps the most conspicuous of these factors was Cusseque's original isolation.
Indeed, we should not forget that the village's isolation created by the civil war played a vital role in the fabric of the local society. Inevitably, it came to influence the way these people interpret and relate to the land.

During the civil war, as military forces, Cusseque's residents were given basic materials for subsistence (e.g. canned food). This was the time when MPLA was seho - an utmost object of respect or, as a resident said, "o pai" (the father). But when the war ended, this system of provision changed radically. Currently, residents must rely on other sources to earn and preserve the means for a living. As I used to be told, "Everything in the land became very important for us". The land in its entirety has become the ultimate seho, the ultimate pai, the most reliable and valuable system of provision to them.

The crucial question that therefore emerges is: How is this everythingness manifested through land practices? In the next section, I will explore one side of these practices: the side in which the residents utilize the land in an undomesticated manner.

\section{Biological Knowledge and the Lived Corporeality of Land}

When the headman of Cusseque - the soba as they are known in Angola - first led me to the village's surrounding savannah and bush, the idea of complete land utilization arose in my mind. The soba stated that valuable means of subsistence were available in almost every square meter we passed through. But what was more interesting was that all the attributes he described were untamed. Trees that were initially indistinguishable from one another to my eyes became transformed into different resources, with different names, different utilities, and different levels of utilization. The same happened with the soil, plants, grass, animals, rocks, and so on. Such a sophisticated biological knowledge, evident in many other residents, reveal that despite the land's untamed character, this was a field of significance for livelihoods. Nothing was nothing and everything was important.

As I will hopefully demonstrate, attempts to understand residents' relational involvement with nonmanipulated land open us a door to access how the local society is ordered through (not by) nature's "given" biotic products.
It is precisely the character of this nonhierarchical relationship between the residents and land that I find troubling reducing to the term "land-use practices". This does not mean that agriculture and other explicit human interventions on the land are not important in Cusseque. Whether it is modified by human capacity or by other means, the land has existential significance in the village. However, my main concern here is to present an alternative and complementary understanding of residents' relationships with nature that extends beyond the management of land's agenda.

In Cusseque, knowledge and utilization are inseparable. Residents' superior understanding of biological living things is inseparable from their direct and exploratory sensorial engagement with them. Unlike so-called techno-scientific knowledge, this mode of knowing seems incoherent and loses value when it is presented as indifferent to the senses. The local practice of medicine is a good example. "You don't learn how to make the cure just by listening or writing it down", a 38-year-woman warned me. "You have to go with me to the forest and get the things yourself. And then, you cook them with your own hands close to me". As the process of learning to make medicaments indicates, biological knowledge is not only invariably related to the employability of that knowledge. It is also associated to the virtue of touch.

This topic extends beyond the main purpose of this article, and certainly deserves a much deeper analysis than I could provide here. Nonetheless, I want to call attention to the idea that, contrary to land use's rationale that attributes value to "wilderness" because of our body-sensorial everyday absence from it (Hailwood 2000: 359), in this case, the "wilderness" of the land is charged with value because it can be experienced tactilely, everyday. By serving as a means of bioliving, the land is valued for its self-ruled capacities that are signified through corporeal sensations. In Cusseque, the food one eats or the residence in which one lives primarily involves a series of tactile contacts. Life in this village is a handmade enterprise derived from the land.

The residents of Cusseque can distinguish between fifty different trees because they actually touch those trees. In so doing, they create an environment of union with the land, which is reflected in the way they utilize each one of the trees as something relevant in their lives. 


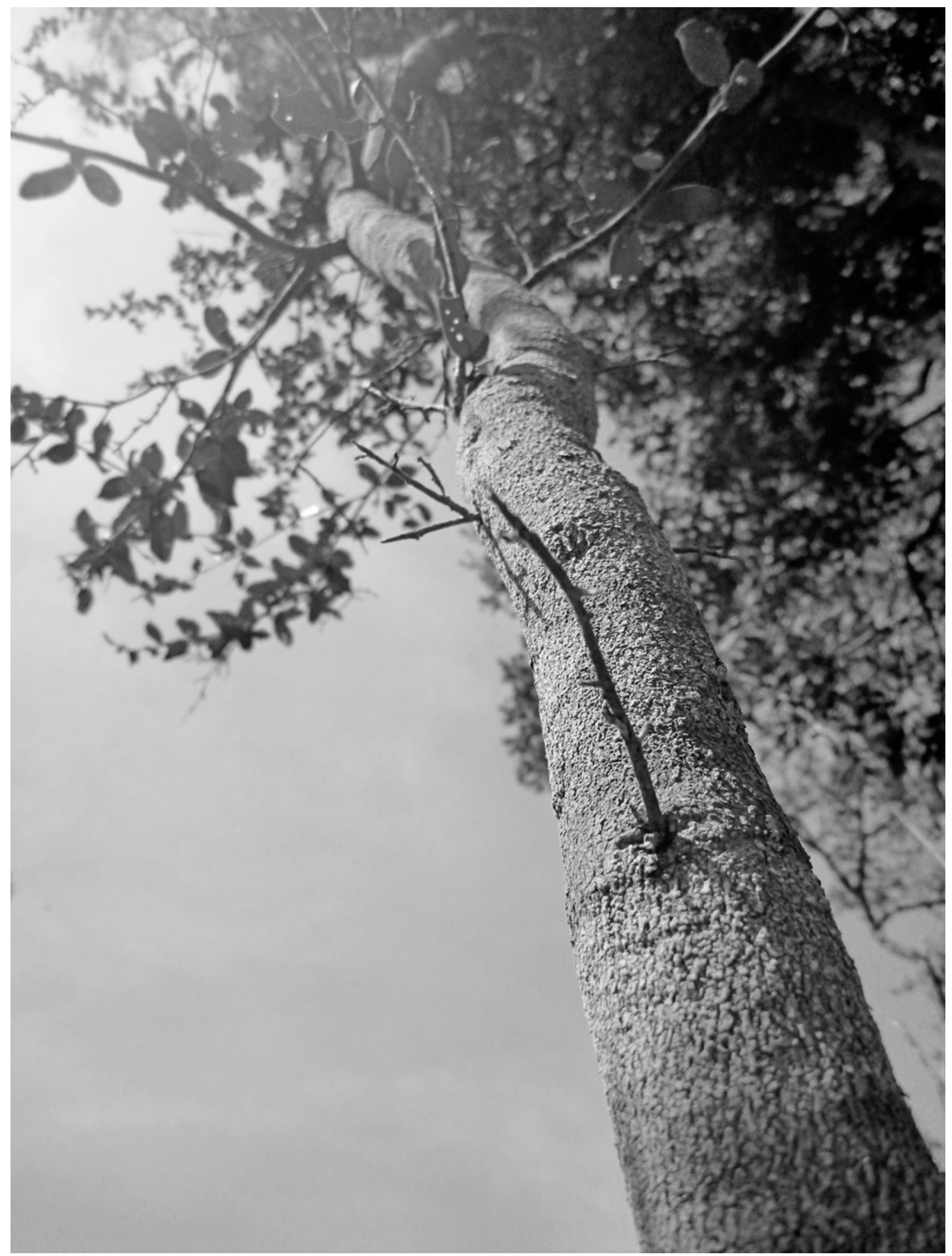

Fig. 1: Muchacha tree in Cusseque (28 June 2011). 
For example, let us consider a type of tree known as muchacha in the Utchokwe language (see Fig. 1). This was by far one of the trees most cited by women in the village, perhaps because it offers great versatility. The leaves of the muchacha are widely utilized for different medicinal purposes. They are also used to create cosmetics. Furthermore, muchacha is commonly used by women to commit suicide. Specifically, they introduce the peeled roots into their vaginas to die. Thus, the knowledgeable bodily utilization of this singular natural tree can lead to outcomes as disparate as health, beauty, and death.

During my first months in the village, I was told that more than fifty different species of natural trees existed in the surrounding area. Six "sticks" (páus, in the original Portuguese), as residents preferred to call them, were highlighted for their carpentry potential (muzungue, muchi, mukula, muambo, mumanga, and mulengo). Four trees were known for their durability and imperviousness to rot in any situation, and thus were valued for their multi-utilizations (mutete, mucagicombomga, mutangula, and mucosso). An additional four trees were said to be important for cooking fuel (munhumbe, mucue, kussamba, and munhanga). Moreover, other trees were valued for bees and honey, ropes, food, domestic utensils, shade, or even for detergent to wash clothes. In regard to the latter, this particular small shrub is called ipungu.

Medicine came at the top of the valueutilization of trees. In addition to muchacha, the residents "trusted" the following species for the production of multiple remedies by utilizing their leaves, trunks, or roots: mussokua, mulima, mundoyo, chikamba, mussalia, mukassa, mugando, muchilauachikafo, mukolo, mufulafula, chilombo, mussambia, mujongolo, mukosso, muzule, kussamba, munhanga, mussokua, mussesse, munhumbe, muto, muсue, muli, mujindo, muhuhu, mualato, mueya, chikuku, chifahakokonha, and mumbumbuji.

All household members participate in gathering activities. The maboque is the non-cultivated (by humans) fruit most commonly utilized by residents. It is a spherical, juicy, sweet-sour, yelloworange fruit that is very popular among residents. Maboque has a hard shell that must be broken to access its inner edible parts. One resident informed me that, if this fruit is picked and eaten after burns or fires have occurred, it can act as a kind of narcotic that will cause people and animals to become "stoned". Other popular fruits provided by local natural reproduction throughout the year include mahuvila, fungo, ngindo, bumbua, paua, tundu, bungo, zele, rocha, and kosso.

By analyzing local discourses in conversations related to fruits, I realized the existence of an illuminating distinction between the rationales that underlie land use and land utilization. For example, when residents referred to harvesting crops in their fields, they commonly employed the words "recollect" and "use" (recolher and usar, in the original Portuguese). However, when they discussed gathering wild fruits, they preferred the terms "seek" and "utilization" (buscar e aproveitamento). In the first case, "recollect" means to collect something that the residents previously cultivated. Thus, crops are implicitly defined as the results of human intervention. No utilization (aproveitamento) occurred here because the land provides the products residents produced on it. This is why it is considered an act of recollection rather than collection; a technical intervention based on predictiveness. Along these lines, the land operates as a medium between human goals and expected results. It becomes a field of dominion.

However, when the residents "seek" wild fruits (not just "recollect" them), they attempt to find something they had not previously cultivated. In this case, this action does not involve using the land to attain the results of their interventions. Rather, it involves residents utilizing the capacities of the land in its self-mode of reproduction. To put otherwise, it involves resorting to the outcomes of the land without attempting to manage those outcomes. "Everything that dies today will be born and grow again tomorrow, naturally", I was told in an informative tone during a gathering, "otherwise there would be nothing; we all would be nothing".

The principle of complete land utilization is evident in the village's infrastructure. In particular, it is obvious in the village housing. Most dwellings are constructed out of wooden sticks tied together with thin strips of tree bark harvested from two different trees: mukues or chikungos. The walls are covered with a specific quality of soil known as muchimbanji. The other two types of soil, muchisseque and chissenguevo, each have different utilization possibilities. Finally, the house is roofed with kalessa. Concretely, in Cusseque, when the grass that surrounds the village becomes higher, larger, and yellow or brown, it becomes a valuable means for habitation. Among other utilizations, "It helps us by protecting us from above," a resident told me. Inhabitants make a clear distinction between kalessa, the thinner grass utilized to create roofs, and manongue, the thicker grass they work with to make fences or housing walls. Depending on each resident's commitment, the entire process that begins with seeking materials and culminates with building a house usually lasts no more than two weeks. I was told the walls made of blocks of muchimbanji are less reliable than walls made of wooden sticks. The latter can "resist" for fifteen years, while houses made of blocks rarely remain liveable for more than ten years.

With respect to the diversity of fauna, residents were particularly aware of the different species of snakes that circulate in the area. Snakes were their most knowledgeable category of animals, which they utilized for food, medicine, and witchcraft. The most mentioned species included Boma, Yengue, Tchihili, Toca, Mucungulu, Fige, Kaliamatamba, Muzuzu, and Chilengamuli. Similar to the muchacha tree, snakes represented the extensive degree of possibilities the land could offer residents to earn livelihoods. They are one of the biggest natural threats because they possess deathly poison. Yet, snakes are also one of the most trustworthy sources of security because the inner oil of some species contains medicinal qualities. Thus, snakes offer a world of different possibilities: Their skins, teeth, meat, and oil are all utilizable resources that can satisfy different purposes. Overall, snakes demonstrate how the notion of living in Cusseque involves residents' capability to incorporate all the surrounding natural constituents ("everything") into a pattern of everydayness.

\section{Gender and Fear of Land}

Land utilization is comprised of corporeal interactions that include symbolic engagements. One such example occurs when boys between the ages of ten and fourteen participate in a rite of passage and become "men". This ritual is held in the mukanda, which is located in the surrounding forest. The kandantche, as a 


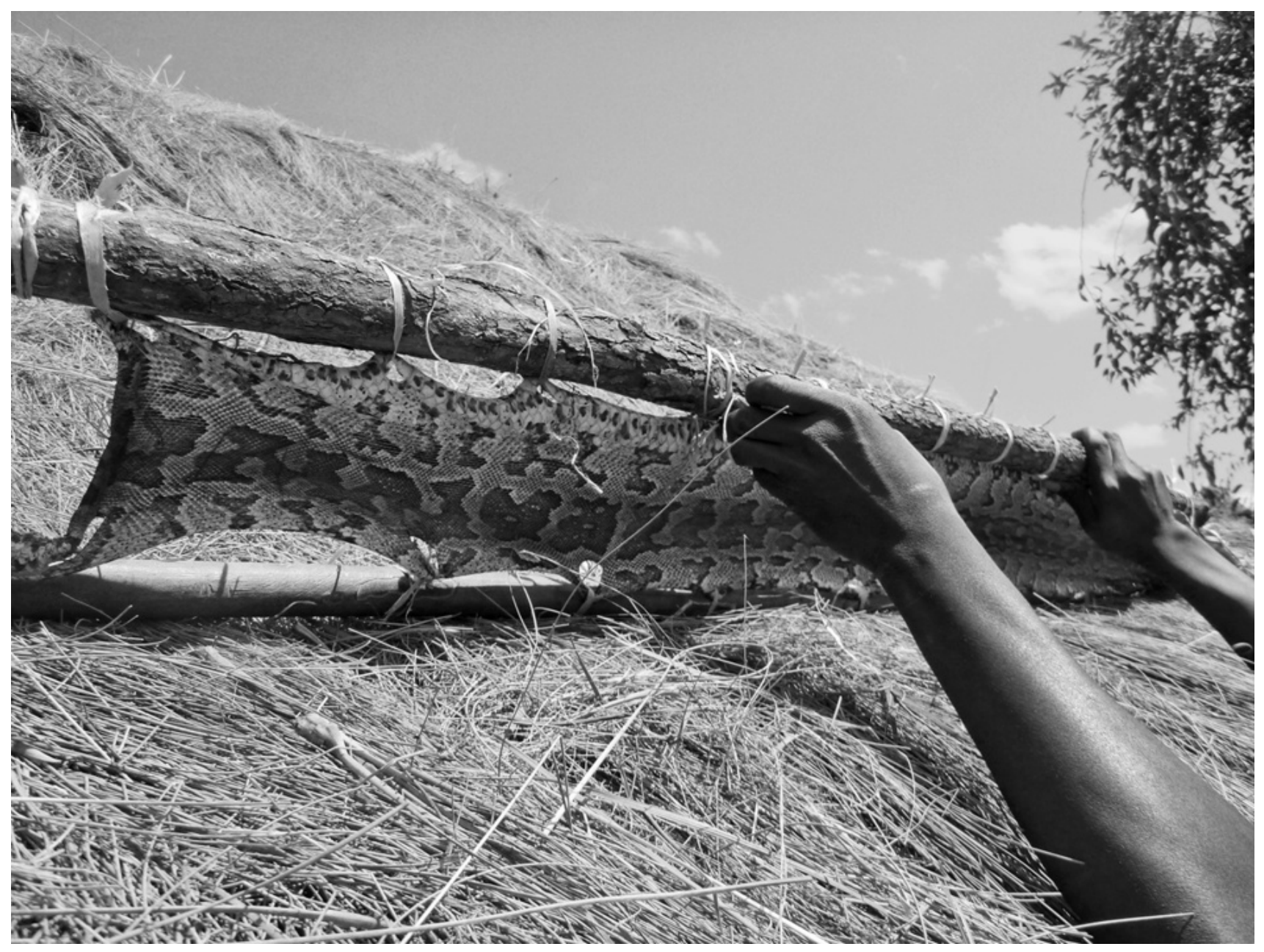

Fig. 2: Snakeskin drying on the roof of a house in Cusseque (9 May 2013).

newly circumcised young man is known, remains in the forest for approximately two weeks. While the kandantche resides in the mukanda, he is generally forbidden to receive visits from women and passes through a series of disciplinary events imposed by other adult men who remain with him.

Commonly referred to as "mata fechada" (closed jungle), the density of the forest and its character as an enclosure is symbolically utilized as a field of education to support the constitution of the complete man. It is a space of becoming. Cusseque's residents rely on the forest-land not only to achieve masculinity but, importantly, to learn about it. The forest is integral to what manhood is about. It participates in the pedagogic process through which humans constitute and define values. To put differently, values do not exist prior to or detached from non-human organic lifeforms, but are actively created through these forms themselves. In general, then, the land embodies a network of cultural forms that can be realized through humans' relational engagement.

Following the same rationale, the residents implicitly associate the river that provides the village's name with womanliness. For example, when they fish, women utilize different fishing tools than men, which imply a different level of engagement with the river. They drag their tambi (women's fishing tool) through the water as part of a technique that requires attentive and prolonged direct interactions with the river. In contrast, men fish in absentia by leaving their mucho (men's fishing tool) on the riverbank overnight. However, what should be emphasized here is that both the mucho and tambi fishing utensils are made entirely out of natural resources collected near the village.

Like the forest, rivers are natural attributes of the land that humans rely on to make a social living. In Cusseque, the forest and rivers epitomize the ecology of symbiotic relationships that occur between humans and non-humans.
Specifically, the forest and rivers participate in the dialectic order through which local gender relations are structured and regulated. It is precisely the integrative character of relationships like those that exist among the rivers, the forest, and the residents that informs the local ecological web of social life.

A great deal can be said about the role and importance of land utilization as part of the regulation of social life. Nevertheless, I could not end this section without mentioning perhaps the most conspicuous social regulatory effect related to land utilization: witchcraft.

Witchcraft regulates people through fear. Basically, each person can potentially exercise a curse against anyone else that might lead to severe illness or death. In theory, this is a social regulatory system that inhibits individual capital accumulation and unbalanced privatization of resources. But what makes witchcraft relevant for the overall purpose in this article is that it enacts social regulation through the principle of 


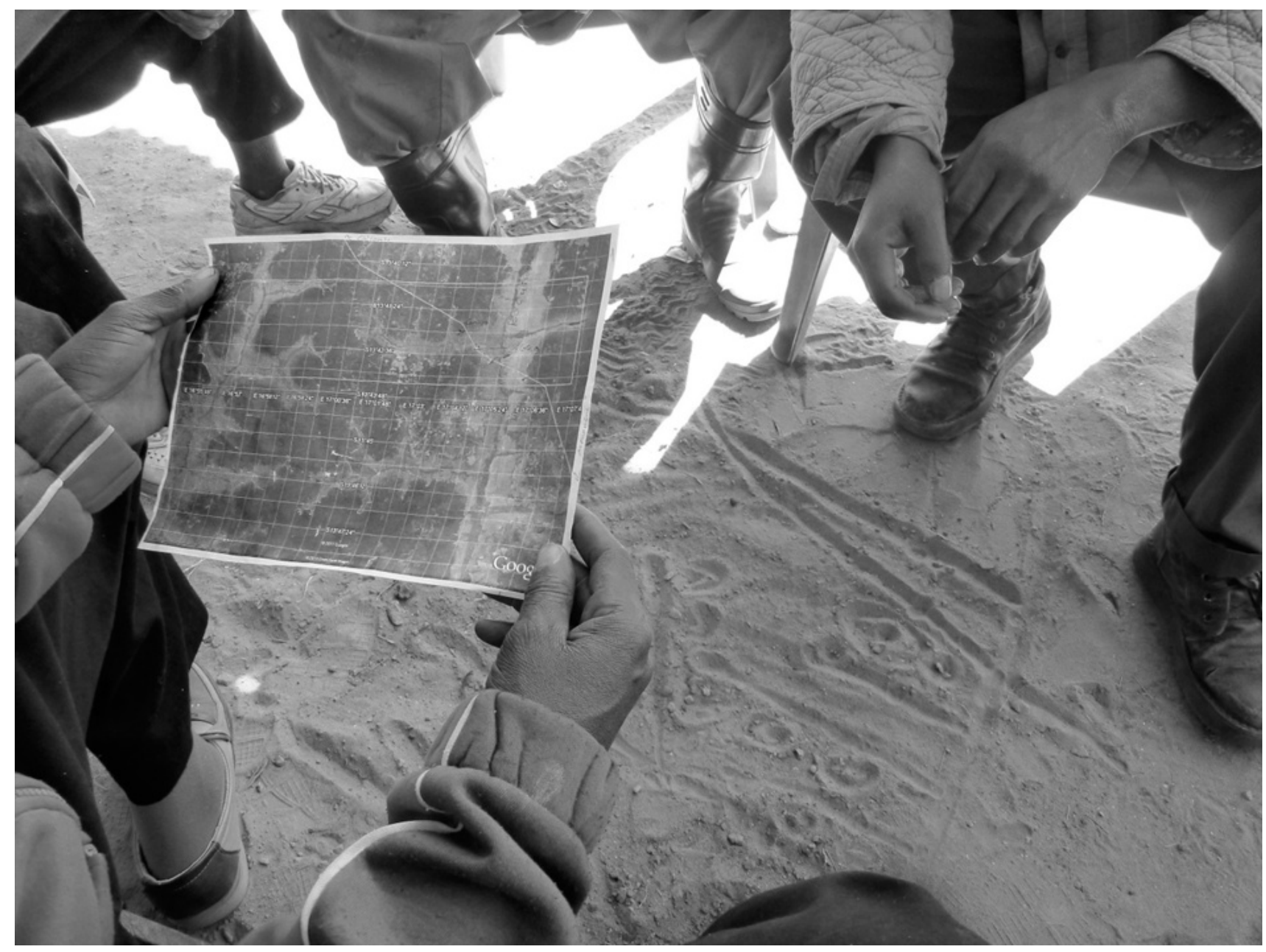

Fig. 3: Cusseque residents contemplating a Google map of the region (11 June 2011)

reliance on natural land's provisions. For example, corn and cassava, both products of the human domestication of the land, are not attributes employed in the service of witchcraft (i.e. for a curse against someone or for a defence against a course). In contrast, the dry skins of different species of snakes (see Fig. 2) that obviously reproduce through "natural processes" are highly valued for witchcraft purposes.

The most fearful and effective products associated with witchcraft are obtained in the "mata fechada" (closed jungle). Furthermore, most curses are performed at night. The sensation of the darkness in the forest's shadows, coupled with the obscurity of the night, generate fear and suspicion. Contemporary Cusseque attests to how the land (including light) can serve as much more than a passive medium that humans can use to organize themselves. Rather, it can act as a leading participant in the production of the social human subject in its own right. Ultimately, the perpetuation of horizontal social order in the village through the regime of witchcraft is not achieved through a process that requires human sovereignty over the land but through a process that requires human adjustability to it.

\section{Values as Conditionally Relational and the Trouble of Mapping Wholeness}

My first general task in Cusseque was to produce a map of the local values of nature. Basically, I asked residents of different ages, both women and men, to describe what they valued most in nature. We would then produce a reliable cartography of valuation that, hopefully, would objectively illuminate environmental valuations. Methodologically, I struggled to grasp local spatial values when I introduced residents to a source and resulting knowledge that originated elsewhere. This became obvious at the very beginning when I showed the soba and another group of residents a Google map of the area (see Fig. 3). Suddenly, this moment of alleged research efficiency became a conspicuous knowledgeformation event. More than inviting them to share their knowledge with me through their own tools of knowing, I implicitly disciplined the residents on spatial thinking based on my own accustomed experience of the conceptualization of space. I made the "real" a technical matter for them and fostered a regime of representation. As Walter Benjamin noted long ago, we "must continually confront the question of representation" (Rajão and Vurdubakis 2013: 151). In not doing so, I realized then, I annulled the potential to learn what I did not know and, therefore, promoted the opposite of my ultimate goal as an anthropologist in Cusseque.

My worries were far from unique. Beginning with Michel Foucault at the top of the celebrities' list, a myriad of authors have considered maps as forms of 
power-knowledge in which meanings and, ultimately, power are imbedded and created (e.g. Culcasi 2012; Kitchin and Dodge 2007; Pickles 2004; Wood 2010; Wood and Fels 2008). Maps are not merely representations of space indeed. Rather, they are active discursive practices that help create values in and of space. Turnbull stated straightforwardly, "Maps have long functioned as Occidental representational archetypes" (2003[2000]: 93), and thus can serve as means of Orientalism (Said 2003[1978]). The ultimate goal of cartography, one could say, is to construct intelligible categories of knowledge and authorize those categories through expert "truths". Perhaps more eloquently than anyone else, J.B. Harley stated, "The practices of visual representation of the map serve to disguise the power that operates in and through cartography. Maps are not empty mirrors, they at once hide and reveal the hand of the cartographer ... The map does not simply itemise the world: it fixes it within a discursive and visual practice of power and meaning" (1988: 277).

This perspective is useful because it sheds light onto the conspicuous directions international NGOs, academic centres, and governmental institutions are taking as they engage in the politics of representing the ecosystem. Moreover, maps are key tools in land use's thinking (e.g. Strand and Moum 2000; Diao and Xiang 2007; Huang et al. 2012). The obvious problem here is that by relying almost exclusively on maps to represent, these institutions and their principles of "land use planning" or "land use decision-making" - even if enacted by morally-charged methods such as "participatory mappings" (IFAD 2009) are legitimizing practices of power imposed on local residents who are unfamiliar with or just do not conceptualize land, space, and nature based on this type of framework. Among other causalities, they foster attitudes about and perceptions of the land subjected to proprietorship and management, which are contrary to land utilization practices. The process of representing the "real" by the use of maps implies the method of "disjunctive synthesis" (Hardt and Negri 2004: 241) that involves the conceptualization of differentiated entities through a process of separation. Furthermore, by universalizing maps as a way of knowing via representation, land use principles legitimize certain mechanisms of power over others. As Foucault famously suggested, power cannot function unless knowledge apparatus are put into circulation (2001: 33-4). Under the mantra of organizing space in rural settings in the "South", maps are contemporary tools of "convenience to manipulate what is resistant" (Cooper 1992: 255) and, ultimately, used to produce governable subjects (both people and the land).

Therefore, I proceeded with the valuation project by adopting a different path. Rather than imposing my method of representation on the residents (the indication of land values on the Google map or the creation of new "participatory maps"), I asked them to present, rather than represent, the surrounding area and their values related to it in any form they wished. Some residents resorted to pens and paper or drew on the sand floor. Many asked me to walk with them while they explained their ideas. Others simply opted to combine body gestures with metaphorical language. In conjunction with a complementary ethnographic analysis of residents' actual modes of action on the land, the local dynamics between values and space became to appear. This marked the first time that I realized I was faced with a way of knowing-valuing that extended beyond the representational paradigm: by representing, we select and necessarily omit elements of a totality. Rather than segmenting the land into multiple and distinct areas of value (Hardt and Negri's disjunctive synthesis), residents opted to present space as an interdependent valueworld. The logic of the pronoun "everything" in residents' talks about the value of land started becoming clear. At the core of this perception of valuewholeness and, by extension, the fact that they did not need to rely on mapping entirety resided an insect: the bee.

\section{Honey}

“The bee produces honey", I was told by a 54-year-woman, "and honey is very, very important for us here. But, the bee only makes honey because she resorts to everything, everywhere". Honey is one of the most valued resources in Cusseque. Its multiple purposes are considered crucial for local livelihoods. A valuation intrinsic to a notion of holism is far from unique. In general, bees are an integral species that contribute to human survival (Moore and Kosut 2012: 29). In addition to honey, humans across the globe rely on the labour of honeybees for the production of other food, particularly through its fertilization of crops. However, advances in factory farming, the use of pesticides and antibiotics, and the effects of (a) modernity, including urbanization, jet travel, and the spread of wireless networks, have made modern human beings, or modern human life, lethal to bees (e.g. Jacobsen 2009; UNEP 2010; Moore and Kosut 2012: 29; Imhoof 2012). Increasing concerns about this issue have appeared in the mainstream radar. The bees' fate has captured minds worldwide and caused the appearance of apocalyptic titles in newspapers and weblogs (e.g. "Can we survive bee extinction?", "World bee decline signals 'sixth major extinction",, or "Extinction of Bees to Bring Extinction of Man?").

Although global concerns continue to grow, the residents of Cusseque are not concerned. "Bees and honey are not lacking here", I was told repeatedly in the village. Among other local meanings and functions, honey serves as an effective disease preventative. Residents trust in honey's medicinal attributes, particularly in its ability to treat coughs, asthma, constipation, allergies, tuberculosis, and gastrointestinal problems. In fact, the period between September and December is considered the healthiest time in Cusseque precisely because it is honey season. One group of residents said, "This is when trees like munhumbe, tchissala in the forest, and kue and missamba closer to the kimbo [the neighbourhood] start producing nectar for the bees". During this period, honey is consumed almost daily in the popular alcoholic drink hidromel, the nonalcoholic drink kissangua, porridge, syrup, or simply in its pure form as it comes direct from the trees: "It can remain ninety days inside the body," the soba told me, "It helps the human body resist life." Furthermore, the honey's worth is explicitly apparent when it gains the function of currency. Indeed, the season for planting the fields also occurs during honey time, between October and December. This is a period in which people hire labourers from outside their families, and honey is widely utilized to pay for their services.

In Cusseque, two sources of honey are available. The most conventional way to obtain honey is to remove it from hives located in treetops situated in the forest area. Another method involves harvesting honey from natural holes in trees. This type of honey is commonly referred to as 


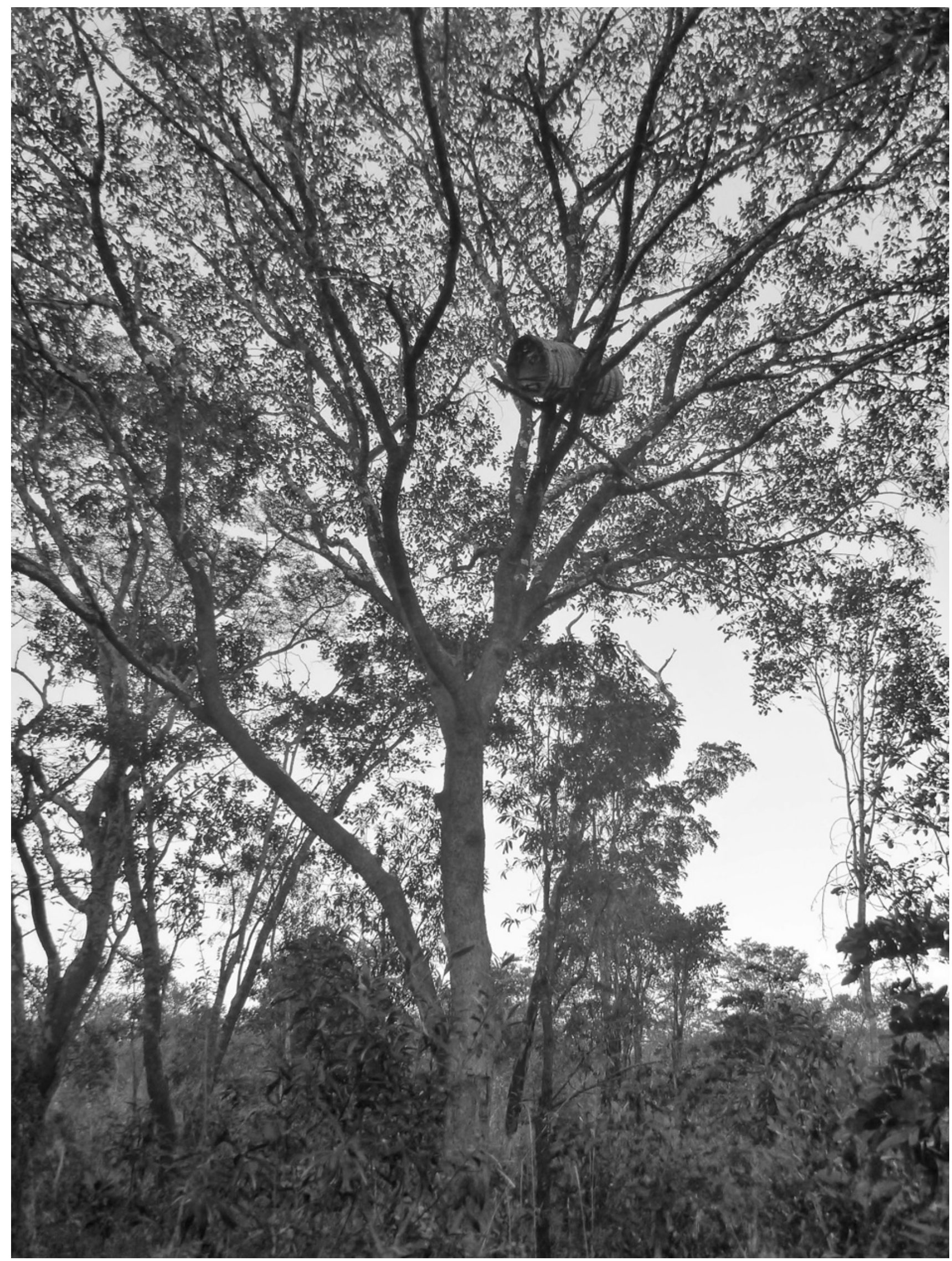

Fig. 4: Bee hive in Cusseque (24 June 2011) 
"wild honey". Both methods are based on the principle of complete land utilization. Even the hives are exclusively created out of elements that originate from the land's self-processes of reproduction (e.g. cork, wood sticks, dry grass, and robes made from tree bark [see Fig. 4]). These hives are viable for at least three years.

Fundamentally, the importance of honey for local livelihoods, its social value, derives from the holistic relationship that bees maintain with the land. Bees gather and carry pollen as well as pollinate fruits, flowers and other vegetation over vast areas. Among other aspects, bees depend on river water, small bushes located at the nhalas, and tall trees in the forest to actually survive and produce honey. This means that one of the most important values in Cusseque is property of the indivisible whole, rather than the virtue of singular sections or the sum of different parts; it relies on the wholeness and borderless dimensions of the land - the "everything, everywhere". Thus, considering bees a ground of value implies that residents recognize a more general constitutive value; a value based on the need for the integrative holism required to ensure that both human and non-human organisms flourish complementarily. In Cusseque, bees cease to be just background and become active participants in the production of values and events of life.

Moore and Kosut argued that "examining bees tells a great deal about us - what we value as society" (2012: 31). Following the same logic, in Cusseque's society, the value of land, as the value of the bees and honey, does not lie in a scale of measurement based on compartmentalization, like it is common in the Euro-North American pragmatics of representation, but in integrative and relational wholeness. After all, what the residents demonstrated by engaging in this valuation process was expressively clear (and, actually, repeatedly stated to me) since the very beginning when they avoided mapping values: "Everything is very important here". In Cusseque, the ecological, the social, and the moral overlap completely. Humans and the land are contained in an integrative whole in which all matter is mutually influenced, vitally and flowingly interrelated. So much so that it validates Clegg's and Hardy's suggestion that, "When we map, we miss" (Rajão and Vurdubakis 2013: 152).

If a general practice of commonality exists in the village, then it should be understood beyond humans' exclusivity and include the land - a system of relational complementarities. As one resident informed me, "Anyone who is 30 years old here means the sun is at noon already". Life is inseparable from everything, and the vital role of complete land utilization practices attest to it.

\section{Final Remarks: The Transmutation of Values}

"We need the tonic of wildness... At the same time that we are earnest to explore and learn all things, we require ... that land and sea be infinitely wild, unsurveyed and unfathomed by us."

(Thoreau 2008[1854]: 415)

Four decades ago, the philosopher John Passmore stressed that we should live "with the fact that natural processes are entirely indifferent to our existence and welfare ... incapable of caring about us" (Hailwood 2000: 354). The village of Cusseque contradicts Passmore and demonstrates how natural processes are, indeed, capable of caring about humans' existence.

In this article, my intention was to highlight the theoretical dangers inherent in generalizing the concept of "land use" to all land practices that benefit rural residents. This generalization actually homogenizes what, in effect, are heterogeneous practices. This is a vision that conceptualizes the potentialities of nature only through human purposive intervention on it, namely by engaging in deliberate activities of management, planning, commensurability, and mapping. Alternatively, I explored the term land utilization, which I believe is more suitable for understanding the relational land practices described above. Although I relied on a situated case study, my overall goal was to draw attention to the potentialities and importance of respecting nature as it exists everywhere. Together with increased human selflimitation (e.g. the restriction of economic growth, industrialization, pollution, and so on), respecting and learning to be nourished by natural processes should be considered a required general precondition for global living. The crucial point that Cusseque attests to is that human societies can develop an everyday living based on their interactions with nature's selfreproduction processes.
However, by presenting grounding arguments to substantiate this conception, I hope I have not provided a homogeneous and romantic impression of a village whose residents perform idyllic and happy relationships with the natural world that surrounds them. In fact, in Cusseque, living is a human endeavour filled with restrictions, contradictions, adversities, and shortages. Life is a daily struggle there. My goal was to demonstrate how the land is utilized in this effort.

As all living organisms, Cusseque society is in motion. The village is not, as no society is, a static compound of individuals who always relate to one another and to the land in the same way. In particular, owing to the post-war politics of progress in the region, conspicuous social transformations that occur in the village, as well as in residents' changing relationships with the land, reflect this basic standpoint. From a society largely ordered by the mathematics of nature's cyclical rhythms to a group of individuals who seek a better living individually, Cusseque is rapidly becoming a society driven by novel ambitions for (a) progress that is stimulated by residents' interactions with new infrastructures created by the national government and private corporations. Specifically, I am referring to the asphalt road finalized in 2010 that crosses the village, the wireless network provided by phone antennas inaugurated in February 2013, or two new banking institutions and a gas station built in the municipality of Chitembo (47 kilometres north of Cusseque). These innovations promote horizons of attainment based upon a constantly renewed sense of insufficiency in both the individual and the collective self that can rarely be fully realized - we are entering the deceptive commodity world here, in which one always wants more than what she or he can actually obtain.

Perhaps the best example of how these ambitions for progress are changing local relationships with and values of the land appears in the emergent production of charcoal in the village. This topic is well beyond the scope of this article, but it is worth brief attention here.

In 2011, when I first arrived in Cusseque, charcoal was a non-subject. No one spoke of it, no one used it, and, to the best of my knowledge, no one produced it. However, two years later, charcoal production has become a common practice in the village. An 
academic scholar in the Angolan city of Huambo informed me that three species of trees from the family Brachystegia (scientific name) primarily "provide" charcoal in the area: omanda, omué, and osamba (in the Ubuntu language). Although these are species that have strong capacities for regeneration which may require between 12 and 16 years to achieve full re-growth, these trees are believed to be in radical decline in the region. Furthermore, because of the high temperatures, the soils on which the kilns used to produce charcoal are built become infertile. It is not surprising, then, that the emerging predominance of charcoal production is now considered one of the main causes of ecological degradation in southeast Angola. It has specifically been related to deforestation of the miombo forest.

In contrast to the land utilization practices described above, in Cusseque, charcoal is not utilized for personal consumption. Rather, it is produced exclusively to satisfy external (market) demands. In these circumstances, charcoal is a commodity, and therefore its value can be quantified, commensurable, divisible (Lambek 2008: 135), and, therefore, mappable. Similar to farms or livestock built for profit, charcoal production is based on the principle of itemization and growth developed at the expense of nature. This results in the progressive transmutation of non-human "lifeworlds" into "post-natural" landscapes.

Nonetheless, from the standpoint of critical environmental thought, the vision of a sustainable future on earth (c.f. Baptista forthcoming) demands a postneoliberal ecopolitics and postcommodity era, rather than a situation in which commodity production and consumption commodity prosumption (cf. Humphreys and Grayson 2008; Baptista 2012: 646-7) - is the prime way of living. Indeed, as we face global concerns for human security and climate change, we all need to imagine new ways of progress. Movements such as De-Growth, Slow Food Revolution, Deep Ecology, or Less is More epitomize this trend in the "West".

In Cusseque, the land utilization practices also hint at an alternative vision of progress based on the way the land is undomestically utilized in virtue of its own capacities. However, in contrast, the utilization of the land for charcoal production in the village, which residents commonly describe as a sign of progress, evidences an obvious and broader conclusion: the extension of the principle of land utilization in everyday, everywhere practices is incompatible with the market society. Therefore, to be effective, land utilization must work in opposition to techno-capitalist ideals. It should be understood and, subsequently, employed as a relational concept within an overall whole that recognizes humans and non-human nature (even on the streets of the biggest metropolises in the world) as independent entities that are, at the same time, irreducible from one another.

In May 2013, on one of my last days in Chitembo, I had a conversation with the head of the local Department of Agriculture about urbanization and forests. At the end of our conversation, he said: "There is a natural logic in things, and not understanding this is the danger. If God planted a mountain in one place, we shouldn't go there and cut that mountain to construct buildings or put whatever is contrary to the nature of that mountain, but just live with it". He made an essential distinction between approaching the land exclusively from a managerial perspective or, alternatively, respecting its ecological sovereignty. Ultimately, the definition of land utilization I have explored here suggests that we must "step back" from a perspective that depends entirely on imperatives that involve human intervention on nature. What is at the core of the politics of progress in postcolonial Angola and elsewhere is the definition and further institutionalization of an ethic in human life: should the land be rearranged at will by humans or does it have an ethos in its own right that humans must consciously subject to? On the face of the global environmental crisis, how can we define the good way to live?

\section{Acknowledgements}

I am very grateful to the population of Cusseque, in particular soba José, as well as to Pena and Mukanda from the administration of Chitembo. I also wish to thank Michael Schnegg and Michael Pröpper for their support at the Department of Social and Cultural Anthropology in the University of Hamburg as well as to the reviewers for their comments on an earlier version of this article. Finally, this article constitutes part of the research project "The Future
Okavango" (TFO) in the Okavango catchment of Angola, Namibia, and Botswana funded by the German Ministry of Science and Education.

\section{References}

Bakhtin, M. (1986): Speech Genres and Other Late Essays. - Austin: University of Texas Press.

Bakhtin, M. (2008): The Dialogic Imagination. - Austin: University of Texas Press.

Baptista, J. (2006): Os Chineses: Percursos Migratórios e Estratégias de Implementação em Portugal [The Chinese: Migratory Routes and their Strategies of Integration in Portugal]. Lisbon: Autonomia 27.

Baptista, J. (2012): The Virtuous Tourist: Consumption, Development, and Nongovernmental Governance in a Mozambican Village. - American Anthropologist 114(4): 639-651. CrossRef

Baptista, J. (Forthcoming): The ideology of sustainability and the globalization of a future. -Time \& Society.

Brinkman, I. (2000): Ways of Death: Accounts of Terror from Angolan Refugees in Namibia. - Africa 70(1): 1-24. CrossRef

Cooper, R. (1992): Formal Organization as Representation: Remote Control, Displacement and Abbreviation. - In: Reed, M. and Hughes, M. [Eds.]: Rethinking Organization: 254-272. London: SAGE.

Culcasi, K. (2012): Mapping the Middle East from Within: (Counter-) Cartographies of an Imperialist Construction. - Antipode 44(4): 1099-1118. CrossRef

Diao, Y., Xiang, W. (2007): How complex can a land suitability map be? International Journal of Geographical Information Science 21(7): 747-755. CrossRef

Diniz, C. (2006[1973]): Características Mesológicas de Angola [Meseological characteristics of Angola]. - Lisbon: IPAD.

FAO and UNEP (1999): The Future of Our Land: Facing the Challenge. - Rome: Food and Agriculture Organization / United Nations Environment Programme.

Foucault, M. (2001): Society must be defended (D. Macey, Trans.). - New York: Picador.

Geir-Harald, S., Svein, O.M. (2000): Compilation and evaluation of a small- 
scale land resource map. - Norsk Geografisk Tidsskrift - Norwegian Journal of Geography 54(4): 148-156. CrossRef

Hailwood, S. (2000): The Value of Nature's Otherness. - Environmental Values 9: 353-372. CrossRef

Hailwood, S. (2012): Alienations and nature. - Environmental Politics 21(6): 882-900. CrossRef

Harman, G. (2005): Guerilla Metaphysics: Phenomenology and the Carpentry of Things. - Illinois: Open Court.

Hardt, M. and Negri, A. (2004): Multitude. - New York: Penguin.

Harley, J.B. (1988): Maps, Knowledge, and Power. - In: Cosgrove, D. [Ed.]: The Iconography of Landscape: 277-312. Cambridge: Cambridge University Press

Huang, Q., Liu, Y., Li, M., Mao, K., Li, F., Chen, Z., Chen, C., Hu, W. (2012): Thematic maps for county-level land use planning in Contemporary China. Journal of Maps 8(2): 185-188. CrossRef

Humphreys, A. and Grayson, K. (2008): The Intersecting Roles of Consumer and Producer: A Critical Perspective on Co-production, Co-creation and Prosumption. - Sociology Compass 2: $1-18$.

IFAD (2009): Good practices in participatory mapping. - Utar Pradesh: International Fund for Agricultural Development.

Imhoof, M. (2012): More than Honey [documentary film]. - Freiburg: OrangePress.

Ingold, T. (2011 [2000]): The Perception of the Environment: Essays on Livelihood, Dwelling and Skill. - New York: Routledge.

Jacobsen, R. (2009): Fruitless Fall: The Collapse of The Honey Bee and the Coming Agricultural Crisis. - New York: Bloomsbury.

Jordan, W. (2005): Autonomy, Restoration, and the Law of Nature. - Heyd, T. [Ed.]: Recognizing the Autonomy of Nature: 189-205. New York: Columbia University Press.

Kitchin, R., Dodge, M. (2007): Rethinking maps. - Progress in Human Geography 31: 331-344. CrossRef

Lambek, M. (2008): Value and virtue. Anthropological Theory 8(2): 133-157. CrossRef

Moore, L. and Kosut, M. (2012): Bees, Border and Bombs: A Social Account of Theorizing and Weaponizing Bees. Hediger, R. [Ed.]: Animals and War: Studies of Europe and North America:
29-43. Boston: Brill Press.

Nail, T. (2010): A Post-Neoliberal Ecopolitics? Deleuze, Guattari, and Zapatismo. - Philosophy Today 54(2): 179-190. CrossRef

Pickles, J. (2004): A History of Spaces: Cartographic Reason, Mapping and the Geo-coded World. - New York: Routledge.

Rabinow, P. (2011): The accompaniment: assembling the contemporary. Chicago: University of Chicago Press.

Rajão, R., Vurdubakis, T. (2013): On the Pragmatics of Inscription: Detecting Deforestation in the Brazilian Amazon. Theory, Culture \& Society 30(4): 151-177.

Said, E. (2003[1978]): Orientalism. London: Penguin.

Steward, J. (1970): The Foundations of Basin-Plateau Shoshonean Society. Swanson, E. [Ed.]: Languages and Cultures of Western North America: Essays on Honour of Sven s. Lilijeblad: 113-151. Pocatello: Idaho State University Press.

Thoreau, H. (2008[1854]): Walden and On the Duty of Civil Disobedience. Auckland: The Floating Press.

Turnbull, D. (2003 [2000]): Masons, Tricksters and Cartographers. London: Routledge.

UNEP (2010): Global Honey Bee Colony Disorder and Other Threats to Insect Pollinators. - Nairobi: UNEP.

Van Diepen, C., Van Keulen, H., Wolf, J., Berkhout, J. (1991): Land evaluation: from intuition to quantification. Advances in Soil Science 15: 139-204. CrossRef

Wood, D. (2010): Rethinking the Power of Maps. - New York: Guilford Press.

Wood, D., Fels, J. (2008): The Natures of Maps. - Chicago: University of Chicago Press. CrossRef

\section{Affiliation}

João Afonso Baptista*

(joao.baptista@uni-hamburg.de)

Department of Social and Cultural

Anthropology, University of Hamburg

Edmund-Siemers-Allee 1 (West)

20146 Hamburg, GERMANY

*Corresponding author 
